\title{
Effect of Stature on Refraction and Ocular Biometry in Chinese Young Adults: The Anyang University Students Eye Study
}

\section{Ningli Wang ( $\nabla$ wningli@vip.163.com )}

Beijing Tongren Hospital https://orcid.org/0000-0002-8933-4482

\section{Shi-Fei Wei}

Beijing Institute of Ophthalmology, Beijing Tongren Hospital, Capital Medical University

\section{Yun-Yun Sun}

Beijing Institute of Ophthalmology, Beijing Tongren Hospital, Capital Medical University

\section{Shi-Ming Li}

Beijing Institute of Ophthalmology, Beijing Tongren Hospital, Capital Medical University

\section{Jian-Ping Hu}

Beijing Institute of Ophthalmology, Beijing Tongren Hospital, Capital Medical University

\section{Kai Cao}

Beijing Institute of Ophthalmoligy, Beijing Tongren Hospital, Capital Medical University

\section{Ji-Yuan Guo}

Anyang Eye Hospital, Henan Province

He Li

Anyang Eye Hospital, Henan Province

\section{Research article}

Keywords: Body stature, Refraction, Ocular biometry, Young adults

Posted Date: May 26th, 2019

DOl: https://doi.org/10.21203/rs.2.9857/v1

License: (c) (i) This work is licensed under a Creative Commons Attribution 4.0 International License. Read Full License 


\section{Abstract}

Background There are few studies reporting the association between stature and ocular biometry as well as cycloplegic refraction in young adults. Our study determined the relationship between stature and ocular biometry as well as cycloplegic refraction in Chinese young adults. Methods This was a school-based study including university students in Anyang, Henan Province, China. Cycloplegic refraction and corneal curvature (CR) were measured using an autorefractor. Ocular biometric parameters, including axial length (AL), anterior chamber depth (ACD), and lens thickness (LT), were measured using a Lenstar LS900. Height and weight were acquired from an annual standardized physical examination, and body mass index (BMI) was calculated from these measurements. Results A total of 5657 (71.0\%) subjects were available for analysis. After adjusting for age, gender, parental myopia, time outdoors, near work and weight, a $1 \mathrm{~cm}$ taller person could be expected to have more negative refraction as -0.023D, a $0.032 \mathrm{~mm}$ increase in $\mathrm{AL}$, a $0.003 \mathrm{~mm}$ increase in $A C D$, a $0.008 \mathrm{~mm}$ increase in $\mathrm{CR}$, and a 0.001 increase in axial length-corneal radius (AL/CR) ratio. With regard to weight, a $1 \mathrm{~kg}$ heavier person was more likely to have less negative refraction as $0.011 \mathrm{D}$, deeper ACD by $0.001 \mathrm{~mm}$ and flatter cornea by $0.002 \mathrm{~mm}$. A similar pattern of significant associations was also found in BMI. Conclusions Compared to those of less height, young adults of greater height tended to have longer eyes, deeper anterior chambers, flatter corneas, higher AL/CR ratio, and more negative refraction after controlling for potential confounders. In contrast, heavier and higher BMI persons were more hyperopic. The differences in stature may partially explain the variation in refraction and ocular biometric parameters.

\section{Introduction}

The ongoing increase in the prevalence of myopia has reached almost epidemic proportions in some areas of East and Southeast Asia in recent decades [1]. In central China, the prevalence rate of myopia was $3.9 \%$ in grade 1 children and $67.3 \%$ in grade 7 children [2]. A higher prevalence of $83.2 \%$ for myopia and $11.1 \%$ for high myopia was found in central Chinese university students [3]. Furthermore, a study on 19-year-old males in South Korea in 2012 showed a myopia rate of 96.5\% [4].Myopia has become a significant issue in public health, and it leads to further vision problems, especially in those with high myopia. Studies have shown that high myopia is associated with pathologic ocular changes, such as myopic macular degeneration, myopic retinopathy and myopic glaucomatous optic neuropathy, all of which can cause blindness and visual impairment [5-7].

A mismatch in biometric parameters of the eyes and the refractive power of these structures may result in refractive error [8-10].The relationship between myopic refractive errors and longer eyes, flatter corneas, deeper vitreous chambers, and thinner lenses has been documented in previous studies [11-13].In a recent study, Zhang et al. demonstrated that variance in AL and height is largely attributable to shared genes [14]. Considering the complex etiology of myopia, not only genetic and environmental factors [15-17] but also body stature may associate with myopia. In several studies, the association between myopia and body stature has been reported, indicating that a greater height was associated with more myopic refractions [1820], whereas other studies have found no association [21-24]. In addition, studies on ocular biometry have indicated that taller persons appeared to have eyes with longer axial lengths as well as greater values for other ocular dimensions, such as longer vitreous chambers and flatter corneas [18, 22, 24, 25]. However, 
investigators have studied the relationship between height and axial length-to-corneal curvature radius, showing that they are not associatied $[23,24,26]$, whereas Saw et al. found that greater height is associated with a higher AL-CR ratio in children [18].

At present, there are few studies reporting these relationships in young adults. Although a number of population-based and school-based studies to investigate the association between body stature and refraction and biometry parameters have been performed, most studies have primarily included young children or adults older than 40 years [18, 22-26]. Furthermore, it has been reported that the ethnic prevalence of myopia in East Asia, such as that in China, is much higher than that in Western countries [27]. Thus, these relationships may also be inconsistent in different ethnic groups and populations. In addition, few studies controlled for potential confounders, such as parental myopia, time outdoors and near work.

This is one of the few large-scale studies in young adults that collected data, including ocular biometry and cycloplegic refraction, from comprehensive ophthalmologic examinations. Here, we describe the relationship between body stature and biometric parameters and cycloplegic refraction in this population.

\section{Methods}

\section{Participants}

The Anyang University Students Eye Study (AUSES) is a university-based, cross-sectional study in which comprehensive ophthalmologic examinations were performed among university students in Anyang, Henan Province, located in central China. The detailed sample selection and methodology have been described previously [3]. Briefly, participants were selected from both the two public universities in Anyang, using random cluster sampling based on grade level. Excluding those students who were in their final-year internships, freshmen to juniors studying on campus are included. These two universities are multidisciplinary universities with undergraduate and graduate degree programs across various disciplines including economics, computing, engineering, foreign languages, chemistry, and art. Finally, a total of 7,971 students underwent comprehensive examinations at their respective school clinics from September 2016 to June 2017. Of the 7,971 participants examined, a total of 5886 (73.8\%) participants with full data of height, weight, number of myopic parents, time outdoors and near work activities, which was required for this study, were included in this analysis. Among the 5886 subjects, 90 of them did not complete the cycloplegic refraction, 139 had not ocular biometry data, leaving 5657 (71.0\%) subjects included for this analysis.

Ethics committee approval was obtained from the Institutional Review Board of Beijing Tongren Hospital, Capital Medical University. All participating students gave their informed consent before participating in the study, according to the Declaration of Helsinki.

\section{Procedures}

During the examinations of each subject, cycloplegia was achieved by using one drop of $1 \%$ cyclopentolate (Alcon), followed by one drop of Mydrin P (Tropicamide 0.5\%, phenylephrine $\mathrm{HCl} 0.5 \%$; Santen 
Pharmaceutical Co., Ltd., Shiga, Japan) and a second drop of $1 \%$ cyclopentolate in intervals of 5 minutes. Thirty minutes after the last drop, if pupillary light reflex was still present or the pupil size was less than 6.0 $\mathrm{mm} 囚 \mathrm{a}$ third drop of $1 \%$ cyclopentolate was administered and the examination was repeated 15 minutes later. Cycloplegic refraction and corneal curvature radius (CR) were performed by an autorefractor (HRK7000 A, Huvitz, Gunpo, South Korea) three times consecutively with average data used for analysis. All 3 readings should be, at most, 0.50 D apart in both the spherical and cylinder components. The spherical equivalent (SE) was calculated by the standard formula of the algebraic sum of the dioptric powers of the sphere and half of the cylinder (sphere $+0.5 \times$ cylinder). The $\mathrm{CR}$ was conducted in the principal meridians to yield the greatest corneal radius of curvature (CR1) and the lowest corneal radius of curvature (CR2). The average of the 2 corneal curvature meridians was calculated for analysis of the CR. Ocular biometric parameters, including axial length (AL), anterior chamber depth (ACD), and lens thickness (LT), were measured using the Lenstar LS900 (Haag-Streit Koeniz, Switzerland). Three repeated measurements were performed, and the average of these was used for analysis. The axial length-corneal radius (AL/CR) ratio was defined as the AL divided by the mean CR. Height and weight were acquired from the results of an annual standardized physical examination at the university, and body mass index (BMI) was calculated (BMI = weight [in kilograms] $/$ height $^{2}$ [in meters]).

An interviewer-administered questionnaire was used to collect information on the number of myopic parents, time outdoors and near work activities $(\mathrm{h} / \mathrm{d})$ of participants. The content of time outdoors and near work activities used in the AUSES were mainly derived from the Anyang Childhood Eye Study (ACES) [2].Certainly, adjustments based on university students were implemented.

\section{Statistical Analyses}

For all analyses, SPSS version 20.0 (SPSS, Chicago, Illinois, USA), was used. Since refractive and biometric data for the right and left eyes correlated highly (SE, 0.91; AL, 0.94; ACD, 0.96; LT, 0.95; CR1, 0.97; CR2, 0.96; and AL-CR, 0.92), analyses were performed on right eyes only. Height, weight and BMI were presented as quintiles, and linear trend tests were performed by entering the median value of each category of body stature as a continuous variable to investigate significance. Univariate analyses were performed to determine associations between height, weight, and BMI with different ocular biometric components and refraction. Multivariate linear regression models, which were controlled for age, gender, parental myopia, time outdoors, and near work, were constructed to evaluate the effect of height, weight and BMI (independent variables) on ocular biometric parameters and refraction (dependent variables). These measures are presented as the mean \pm SD. A two-sided P-value of $<0.05$ was considered statistically significant.

\section{Results}

A total of 5657 (71.0\%) subjects aged 16 to 26 years were included in this analysis. The mean age for all subjects was $20.23 \pm 1.50$ years. Table 1 shows a comparison of characteristics between included and excluded subjects. Subjects included in our analysis were older and taller compared with those excluded from the analysis. The mean refraction, axial length, anterior chamber depth, lens thickness, corneal 
curvature radius, and axial length-corneal radius ratio were $-2.96 \pm 2.47 \mathrm{D}$ (range, -14.50 to $+9.63 \mathrm{D}$ ), $24.78 \pm 1.20 \mathrm{~mm}$ (range, 19.14 to $29.46 \mathrm{~mm}$ ), $3.23 \pm 0.25 \mathrm{~mm}$ (range, 2.18 to $4.27 \mathrm{~mm}$ ), $3.47 \pm 0.18 \mathrm{~mm}$ (range, 2.80 to $4.30 \mathrm{~mm}$ ), $7.72 \pm 0.26 \mathrm{~mm}$ (range, 6.86 to $9.29 \mathrm{~mm}$ ), and $3.21 \pm 0.15$ (range, 2.58 to 3.82 ), respectively.

The correlations of height, weight and BMI with demographic parameters, spherical equivalent refraction, and ocular biometric parameters were shown in Table 2 . Height and weight were positively correlated with age, time outdoors, near work, spherical equivalent refraction, axial length, anterior chamber depth, and corneal radius of curvature and negatively correlated with female sex, but they were not correlated with either parental myopia or lens thickness. Height was also significantly correlated with axial length-corneal radius ratio. BMI was correlated with the same variables as those with which weight was correlated, with the exception of age and parental myopia. Some values of correlations were low but statistically significant.

The mean values of refraction and ocular biometry among persons categorized by quintiles of height, weight, and $\mathrm{BMI}$ are shown in Table 3. Height was not significantly associated with refraction, whereas heavier and higher $\mathrm{BMI}$ persons tended to have a less myopic refraction $(P=0.001)$. In comparison with persons in the first quintile for height, persons in the fifth quintile for weight and BMI had eyes with less negative refraction by $0.31 \mathrm{D}$. In general, taller, heavier and higher BMI persons had longer axial lengths, deeper anterior chambers, and flatter corneas than did shorter, lighter and lower BMI persons. Furthermore, taller persons also had thinner lenses and higher AL-CR ratios than did shorter persons, but weight and BMI were not associated with lens thickness or AL-CR ratio. In comparison with persons in the first quartile for height, persons in the fifth quintile for height had eyes with axial lengths that were $0.86 \mathrm{~mm}$ longer, anterior chambers $0.12 \mathrm{~mm}$ deeper, lenses $0.02 \mathrm{~mm}$ thinner, radii of curvature $0.23 \mathrm{~mm}$ longer, and AL-CR ratios that were 0.02 higher. The ALs were $0.67 \mathrm{~mm}$ longer, anterior chambers were $0.11 \mathrm{~mm}$ deeper, and radii of curvature were $0.19 \mathrm{~mm}$ longer for persons whose weights were in the fifth quintile compared to those whose weights were in the first quintile. A similar pattern of significant associations was found between $\mathrm{BMI}$ and ocular biometry status.

Table 4 shows the regression models. Each value represents the result of a separate regression model, with the individual refraction or ocular biometric components as the dependent variable and height, weight, or BMI as the independent variable, adjusting for other covariates. In the final model, after adjusting for age, gender, parental myopia, time outdoors, near work, and weight, a $1 \mathrm{~cm}$ taller person could be expected to have more negative refraction as $-0.023 \mathrm{D}$, a $0.032 \mathrm{~mm}$ increase in $\mathrm{AL}$, a $0.003 \mathrm{~mm}$ increase in $A C D$, a $0.008 \mathrm{~mm}$ increase in $\mathrm{CR}$, and a 0.001 increase in $\mathrm{AL} / \mathrm{CR}$ ratio. No significant association was found between height and LT. With regard to weight, a $1 \mathrm{~kg}$ heavier person was more likely to have less negative refraction as 0.011 $D$, a $0.001 \mathrm{~mm}$ deeper ACD, and a $0.002 \mathrm{~mm}$ flatter cornea. However, weight was not significantly associated with AL, LT or AL/CR ratio. A similar pattern of significantly associations was found for BMI. A $1 \mathrm{~kg} / \mathrm{m}^{2}$ higher person was more likely to have less negative refraction as $0.030 \mathrm{D}$, a $0.003 \mathrm{~mm}$ deeper ACD, and a $0.005 \mathrm{~mm}$ flatter cornea. Plots of residual values against fitted values indicated that the model assumptions were met.

\section{Discussion}


In this study, we provided large-scale data on the association between body stature and biometry parameters as well as cycloplegic refraction in young adults aged 16 to 26 years in mainland China. Furthermore, we adjusted the analyses for several potential confounders, such as time outdoors, near work and parental myopia. After adjusting for age, gender, parental myopia, time outdoors, near work, and weight, we found that taller persons had eyes with more negative refractions, longer axial lengths, deeper anterior chambers, flatter corneas, and higher AL/CR ratio, but this relationship was lost between height and lenses thickness. Weight and BMI were associated with less negative refractions, deeper anterior chambers and flatter cornea, but no strong associations with axial length, lenses thickness or AL/CR ratio after controlling for age, gender, parental myopia, time outdoors, near work, and height.

Previous reports have shown an association between myopia and greater height in adults and children [18, 28]. However, other studies have shown no such relationship between refraction and height [4, 22-24]. After adjusting for age, gender, parental myopia, time outdoors, near work, and weight, we found that a $1 \mathrm{~cm}$ taller person could be expected to have more negative refraction (-0.023 D) in young adults. In a school-based study of 1449 Singapore Chinese children aged 7 to 9 years, Saw et al. found that taller girls tended to have more negative refraction, which was shown in multiple linear regression models [18]. However, some studies in adults older than 40 years did not find an association between height and refraction [22, 24]. In previous studies, one hypothesis proposed for the inconsistency of the relationship is that higher socioeconomic status may be associated with a higher education level and better nutrition. Taller persons are more likely to have better nutrition, and the prevalence of myopia is associated with a higher education level, and thus taller persons and more myopic refraction are independent consequences of a higher socioeconomic status [18, 22-24].Therefore, it is suggested that the relationship observed might be affected by these factors that independently affect height and refraction rather than by the direct relationship between height and refraction.

In previous studies of children and adults, it was found that taller persons were more likely to have longer axial lengths, deeper anterior chambers, and flatter corneas [22, 25, 29]. After adjusting for age, gender, parental myopia, time outdoors, near work, and weight, this relationship was also found in this study, indicating an overall increase in eye globe size of taller persons. A related hypothesis to explain these associations is that the changes in eye size may occur concomitantly with overall growth and development [30]. Except for these single parameters, we found that height in Chinese young adults was also related to $\mathrm{AL} / \mathrm{CR}$ ratio, which represented the overall size of eyes. However, previous reports of the association between height and $\mathrm{AL} / \mathrm{CR}$ ratio are inconsistent. Some studies suggested no relationship between height and $\mathrm{AL} / \mathrm{CR}$ ratio $[24,26]$, whereas Saw et al. found a significant association between height and AL/CR ratio in Singapore Chinese school children aged 7 to 9 years, but this relationship was shown only in girls [18]. Different ages, refractive errors and sample sizes, as well as the lack of controlling for confounding variables in these studies, may contribute to the conflicting results. A traditional hypothesis has suggested that the corneal radius changes flatter to compensate for the elongation of the axial length to maintain images on the retina $[31,32]$. The mismatch of this process results in myopia due to the axial length increasing beyond the total optical power of the cornea and lens [30]. In our study, height was strongly associated with both axial length and refraction, as well as with the AL/CR ratio, so this suggests that height and eye growth may have a potentially shared mechanism. 
The relationship of weight and BMI with refraction and ocular biometry has not been reported as much as that of height with refraction and ocular biometry. Although certain studies discovered no relationship between weight and BMI with refraction [23,33], others found the similar pattern of significant relationships between weight, $\mathrm{BMI}$ and refraction with our study $[18,22]$. In adult Chinese residents in Singapore, Wong et al. reported that heavier and more obese (higher BMI) persons were more hyperopic [22]. Consistently, we also found that heavier persons were more likely to be hyperopic than were lighter persons in the final model. As for ocular biometric parameters, we did not find a significant relationship of weight and BMI with AL, but weight and BMI were significantly related to $C R$ and $A C D$. Wong et al. found that weight and BMI were not related to those ocular biometric parameters [22], whereas Wu et al. found a strong association between weight and AL, CR and ACD after adjusting for age and sex, but this association was not found between BMI and ACD [24]. The relationship of weight and BMI with refraction and ocular biometry is likely to be complex. There may be other confounding effects resulting from the apparent relationship.

The strengths of our study included a large sample size and controlling for potential confounders, especially conducting in young adults. However, our study also has several limitations. Firstly, since it was a crosssectional designed study, it was unable to provide any longitudinal information assessing determinants of refraction, ocular biometry and body stature. Secondly, it was conducted as a university-based investigation rather than a population-based investigation. Thus, there may be selection bias.

\section{Conclusions}

This study found that young adults with higher height tended to have longer eyes, deeper anterior chambers, flatter corneas, higher AL/CR ratio, and more negative refraction than those with lesser height after controlling for potential confounders. Strong associations between weight, BMI and anterior chamber depth and corneal curvature were also found. However, heavier persons or those with higher BMI were more likely to be more hyperopic than lighter persons or those with lower BMI. These differences in stature may partially explain the variation in refraction and ocular biometry.

\section{Abbreviations}

CR: Corneal curvature; AL: Axial length; ACD: Anterior chamber depth; LT: Lens thickness; BMI: Body mass index; AL/CR: Axial length-corneal radius; SE: Spherical equivalent

\section{Declarations}

\section{Ethics approval and consent to participate}

Ethics committee approval was obtained from the Institutional Review Board of Beijing Tongren Hospital, Capital Medical University. All participating students gave their informed consent before participating in the study, according to the Declaration of Helsinki. 


\section{Consent for publication}

Not applicable.

\section{Availability of data and material}

The data of the current study are available from the corresponding author on reasonable request.

\section{Competing interests}

The authors declare that they have no competing interests.

\section{Funding}

This study was supported by the Integration, Translation and Development on Ophthalmic Technology (Jingyiyan 2016-5), the Capital Health Research and Development of Special (2016-4-2056) and the Major International (Regional) Joint Research Project of the National Natural Science Foundation of China (81120108007).

\section{Authors' contributions}

WSF conceived of the study, collected the data and drafted the manuscript. SYY conceived of the study, collected the data and revised the manuscript. WSF, HJP, CK performed the statistical analysis and interpretation of data. GJY and LH collected the data and critical revision of the manuscript. LSM and WNL conceived of the study, and critical revision of the manuscript. WNL took responsibility of the research. All authors have read and approved the manuscript.

\section{Acknowledgements}

The Authors wish to thank the Anyang University Students Eye Study Group.

\section{References}

1. Morgan IG, Ohno-Matsui K, Saw SM. Myopia. Lancet. 2012; 379: 1739-48.

2. Li SM, Liu LR, Li SY, Ji YZ, Fu J, Wang Y, et al. Design, methodology and baseline data of a school-based cohort study in Central China: the Anyang Childhood Eye Study. Ophthalmic Epidemiol. 2013; 20: 348-59.

3. Wei S, Sun Y, Li S, Hu J, Yang X, Lin C, et al. Refractive Errors in University Students in Central China: The Anyang University Students Eye Study. Invest Ophthalmol Vis Sci. 2018; 59: 4691-700. 
4. Jung SK, Lee JH, Kakizaki H, Jee D. Prevalence of myopia and its association with body stature and educational level in 19-year-old male conscripts in seoul, South Korea. Invest Ophthalmol Vis Sci. 2012; 53: 5579-83.

5. Xu L, Wang Y, Wang S, Wang Y, Jonas JB. High myopia and glaucoma susceptibility the Beijing Eye Study. Ophthalmology. 2007; 114: 216-20.

6. Liu HH, Xu L, Wang YX, Wang S, You QS, Jonas JB. Prevalence and progression of myopic retinopathy in Chinese adults: the Beijing Eye Study. Ophthalmology. 2010; 117: 1763-8.

7. Wong TY, Ferreira A, Hughes R, Carter G, Mitchell P. Epidemiology and disease burden of pathologic myopia and myopic choroidal neovascularization: an evidence-based systematic review. Am J Ophthalmol. 2014; 157: 9-25 e12.

8. Lin LLK, Shih YF, Lee YC, Hung PT, Hou PK. Changes in ocular refraction and its components among medical students - A 5-year longitudinal study. Optometry and Vision Science. 1996; 73: 495-8.

9. Wickremasinghe S, Foster PJ, Uranchimeg D, Lee PS, Devereux JG, Alsbirk PH, et al. Ocular biometry and refraction in mongolian adults. Invest Ophthalmol Vis Sci. 2004; 45: 776-83.

10. Warrier S, Wu HM, Newland HS, Muecke J, Selva D, Aung T, et al. Ocular biometry and determinants of refractive error in rural Myanmar: the Meiktila Eye Study. Br J Ophthalmol. 2008; 92: 1591-4.

11. Zadnik K, Mutti DO, Friedman NE, Qualley PA, Jones LA, Qiu PH, et al. Ocular predictors of the onset of juvenile myopia. Invest Ophthalmol Vis Sci. 1999; 40: 1936-43.

12. McBrien NA, Adams DW. A longitudinal investigation of adult-onset and adult-progression of myopia in an occupational group - Refractive and biometric findings. Invest Ophthalmol Vis Sci. 1997; 38: 321-33.

13. Li SM, Li SY, Kang MT, Zhou YH, Li H, Liu LR, et al. Distribution of Ocular Biometry in 7-and 14-Year-Old Chinese Children. Optometry and Vision Science. 2015; 92: 566-72.

14. Zhang JA, Hur YM, Huang WY, Ding XH, Feng K, He MG. Shared Genetic Determinants of Axial Length and Height in Children The Guangzhou Twin Eye Study. Arch Ophthalmol-Chic. 2011;129: 63-8.

15. Stambolian D. Genetic susceptibility and mechanisms for refractive error. Clinical Genetics. 2013; 84 : $102-8$.

16. Pan CW, Ramamurthy D, Saw SM. Worldwide prevalence and risk factors for myopia. Ophthal Physl Opt. 2012; 32: 3-16.

17. Mutti DO, Mitchell GL, Moeschberger ML, Jones LA, Zadnik K. Parental myopia, near work, school achievement, and children's refractive error. Invest Ophthalmol Vis Sci. 2002; 43: 3633-40.

18. Saw SM, Chua WH, Hong CY, Wu HM, Chia KS, Stone RA, et al. Height and its relationship to refraction and biometry parameters in Singapore Chinese children. Invest Ophthalmol Vis Sci. 2002; 43: 1408-13. 
19. Goldschimdt E. Myopia and height. Acta Ophthalmol. 1966;44:751-61.

20. Teikari JM. Myopia and stature. Acta Ophthalmol (Copenh). 1987; 65: 673-6.

21. Alsbirk PH. Refraction in adult West Greenland Eskimos. A population study of spherical refractive errors, including oculometric and familial correlations. Acta Ophthalmol (Copenh). 1979; 57: 84-95.

22. Wong TY, Foster PJ, Johnson GJ, Klein BEK, Seah SKL. The relationship between ocular dimensions and refraction with adult stature: The Tanjong Pagar survey. Invest Ophthalmol Vis Sci. 2001; 42: 1237-42.

23. Ojaimi E, Morgan IG, Robaei D, Rose KA, Smith W, Rochtchina E, et al. Effect of stature and other anthropometric parameters on eye size and refraction in a population-based study of Australian children. Invest Ophthalmol Vis Sci. 2005; 46: 4424-9.

24. Wu HM, Gupta A, Newland HS, Selva D, Aung T, Casson RJ. Association between stature, ocular biometry and refraction in an adult population in rural Myanmar: the Meiktila eye study. Clinical and Experimental Ophthalmology. 2007; 35: 834-9.

25. Saw SM, Carkeet A, Chia KS, Stone RA, Tan DTH. Component dependent risk factors for ocular parameters in Singapore Chinese children. Ophthalmology. 2002; 109: 2065-71.

26. Huang D, Chen XJ, Gong Q, Yuan CQ, Ding H, Bai J, et al. Ocular biometric parameters among 3-year-old Chinese children: testability, distribution and association with anthropometric parameters. Scientific Reports. $2016 ; 6$.

27. Holden BA, Fricke TR, Wilson DA, Jong M, Naidoo KS, Sankaridurg P, et al. Global Prevalence of Myopia and High Myopia and Temporal Trends from 2000 through 2050. Ophthalmology. 2016; 123: 1036-42.

28. Rosner M, Laor A, Belkin M. Myopia and stature: findings in a population of 106,926 males. Eur J Ophthalmol. 1995; 5: 1-6.

29. Lee KE, Klein BE, Klein R, Quandt Z, Wong TY. Association of age, stature, and education with ocular dimensions in an older white population. Arch Ophthalmol. 2009; 127: 88-93.

30. Larsen JS. The sagittal growth of the eye. IV. Ultrasonic measurement of the axial length of the eye from birth to puberty. Acta Ophthalmol (Copenh). 1971; 49: 873-86.

31. Benjamin B, Davey JB, Sheridan M, Sorsby A, Tanner JM. Emmetropia and its aberrations; a study in the correlation of the optical components of the eye. Spec Rep Ser Med Res Counc (G B). 1957; 11: 1-69.

32. Sorsby A, Benjamin B, Sheridan M, Stone J, Leary GA. Refraction and its components during the growth of the eye from the age of three. Memo Med Res Counc. 1961; 301: 1-67.

33. Foster PJ, Broadway DC, Hayat S, Luben R, Dalzell N, Bingham S, et al. Refractive error, axial length and anterior chamber depth of the eye in British adults: the EPIC-Norfolk Eye Study. Br J Ophthalmol. 2010; 94 :

827-30. 


\section{Tables}

Table 1 Comparison of subjects included in and excluded from data analyses

\begin{tabular}{|c|c|c|c|}
\hline Variable & $\begin{array}{l}\text { Included } \\
(\mathrm{n}=5657)\end{array}$ & $\begin{array}{l}\text { Excluded } \\
(\mathrm{n}=229)\end{array}$ & $P_{*}$ \\
\hline Age, $y$ & $20.23 \pm 1.50$ & $19.70 \pm 1.40$ & $\square 0.001$ \\
\hline Sex, male & 2075 (36.7) & $71(31.0)$ & 0.093 \\
\hline Height, $\mathrm{cm}$ & $166.24 \pm 7.94$ & $164.95 \pm 8.12$ & 0.017 \\
\hline Weight, kg & $57.89 \pm 10.03$ & $57.08 \pm 10.94$ & 0.237 \\
\hline BMI, $\mathrm{kg} / \mathrm{m}^{2}$ & $20.85 \pm 2.56$ & $20.85 \pm 2.75$ & 0.994 \\
\hline Parental myopia, n(\%) & & & 0.132 \\
\hline None & $4947(87.45)$ & $192(83.8)$ & \\
\hline Either & $634(11.21)$ & $31(13.5)$ & \\
\hline Both & $76(1.3)$ & $6(2.6)$ & \\
\hline Time outdoors, h/d & $1.52 \pm 1.29$ & $1.61 \pm 1.38$ & 0.295 \\
\hline Near work, h/d & $3.76 \pm 2.36$ & $3.90 \pm 2.28$ & 0.381 \\
\hline
\end{tabular}

Data are presented as the mean \pm SD or $n(\%)$, as appropriate for the variable.

* $P$ based on Chi-square test or T-test, as appropriate. 
Table 2 Correlation analysis between body stature and sociodemographic variables,

refraction and ocular biometry

\begin{tabular}{llll}
\hline & \multicolumn{3}{c}{ Spearman Correlation Coefficient } \\
\cline { 2 - 4 } & Height $(\mathrm{cm})$ & Weight $(\mathrm{kg})$ & BMI $\left(\mathrm{kg} / \mathrm{m}^{2}\right)$ \\
\hline Age & $0.047 \dagger$ & $0.029^{*}$ & 0.002 \\
Sex (female) & $-0.765 \dagger$ & $-0.621 \dagger$ & $-0.223 \dagger$ \\
Parental myopia & -0.002 & 0.018 & $0.034^{*}$ \\
Time outdoors & $0.113 \dagger$ & $0.104 \dagger$ & $0.058 \dagger$ \\
Near work & $0.069 \dagger$ & $0.077 \dagger$ & $0.052 \dagger$ \\
SE (D) & $0.026^{*}$ & $0.052 \dagger$ & $0.049 \dagger$ \\
AL (mm) & $0.239 \dagger$ & $0.184 \dagger$ & $0.058 \dagger$ \\
ACD (mm) & $0.161 \dagger$ & $0.138 \dagger$ & $0.058 \dagger$ \\
LT (mm) & -0.024 & -0.017 & 0.001 \\
CR (mm) & $0.308 \dagger$ & $0.263 \dagger$ & $0.111 \dagger$ \\
AL/CR ratio & $0.036^{*}$ & 0.003 & -0.025 \\
\hline
\end{tabular}

SE, spherical equivalents

* Significant at $P \square 0.05$

† Significant at $P \square 0.001$ 
Table 3 Mean ocular biometry measurements and refraction by quintiles of stature

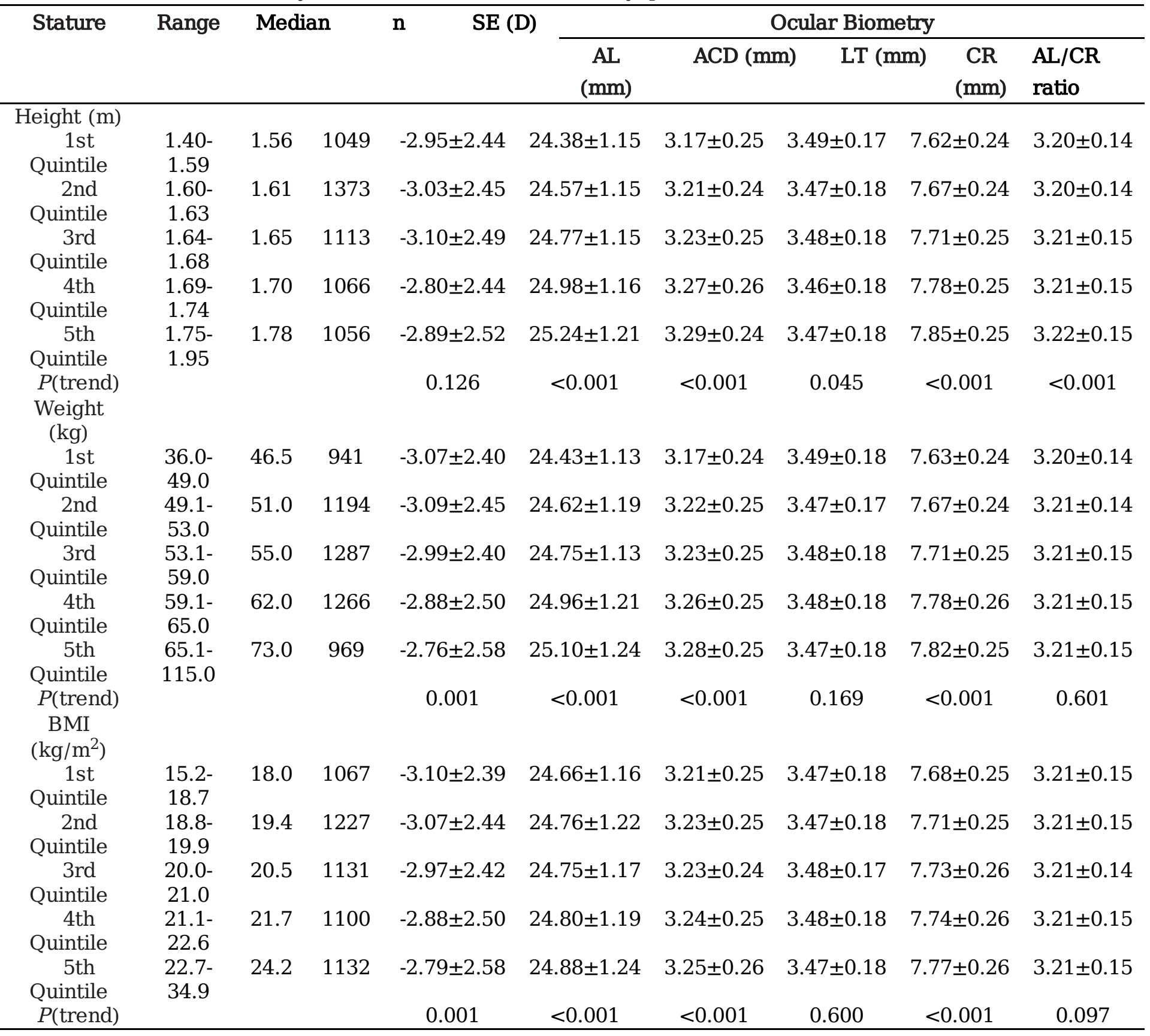


Table 4 Linear regression models of refraction and ocular biometry by height, weight, and BMI

\begin{tabular}{|c|c|c|c|c|c|c|c|}
\hline Variable & Crude Data & $P$ & $\begin{array}{l}\text { Adjusted for Age } \\
\text { and Sex }\end{array}$ & $P$ & $\begin{array}{c}\text { Adjusted for Age, } \\
\text { Sex, PM, TO, NW } \\
\text { and Weight or } \\
\text { Height* }\end{array}$ & $P$ & $\begin{array}{c}\text { R2 } \\
\text { Final } \\
\text { Models } \dagger\end{array}$ \\
\hline \multicolumn{8}{|l|}{$\begin{array}{l}\text { Height } \\
(\mathrm{cm})\end{array}$} \\
\hline $\begin{array}{l}\mathrm{SE} \\
\text { (D) }\end{array}$ & $0.008(-0.001,0.016)$ & 0.069 & $-0.018(-0.03,-0.005)$ & 0.006 & $-0.023(-0.037,-0.009)$ & 0.002 & 0.058 \\
\hline $\begin{array}{c}\mathrm{AL} \\
(\mathrm{mm})\end{array}$ & $0.037(0.033,0.041)$ & $<0.001$ & $0.033(0.027,0.039)$ & $<0.001$ & $0.032(0.025,0.039)$ & $<0.001$ & 0.097 \\
\hline $\begin{array}{l}\text { ACD } \\
(\mathrm{mm})\end{array}$ & $0.005(0.004,0.006)$ & $<0.001$ & $0.003(0.002,0.004)$ & $<0.001$ & $0.003(0.001,0.004)$ & 0.001 & 0.032 \\
\hline $\begin{array}{c}\mathrm{LT} \\
(\mathrm{mm})\end{array}$ & $-0.001(-0.001,0.00)$ & 0.055 & $0.000(-0.001,0.001)$ & 0.850 & $0.000(-0.001,0.001)$ & 0.952 & 0.008 \\
\hline $\begin{array}{r}\mathrm{CR} \\
(\mathrm{mm})\end{array}$ & $0.010(0.009,0.011)$ & $<0.001$ & $0.008(0.007,0.010)$ & $<0.001$ & $0.008(0.006,0.009)$ & $<0.001$ & 0.109 \\
\hline $\begin{array}{l}\mathrm{AL} / \mathrm{CR} \\
\text { ratio } \\
\text { Weight } \\
(\mathrm{kg})\end{array}$ & $0.001(0.000,0.001)$ & 0.007 & $0.001(0.000,0.002)$ & 0.031 & $0.001(0.000,0.002)$ & 0.025 & 0.041 \\
\hline $\begin{array}{l}\text { SE } \\
\text { (D) }\end{array}$ & $0.010(0.004,0.017)$ & 0.002 & $0.002(-0.006,-0.01)$ & 0.694 & $0.011(0.002,0.020)$ & 0.017 & 0.058 \\
\hline $\begin{array}{c}\mathrm{AL} \\
(\mathrm{mm})\end{array}$ & $0.023(0.019,0.026)$ & $<0.001$ & $0.012(0.008,0.016)$ & $<0.001$ & $0.002(-0.002,0.007)$ & 0.285 & 0.097 \\
\hline $\begin{array}{l}\text { ACD } \\
(\mathrm{mm})\end{array}$ & $0.004(0.003,0.004)$ & $<0.001$ & $0.002(0.001,0.002)$ & $<0.001$ & $0.001(0.000,0.002)$ & 0.029 & 0.032 \\
\hline $\begin{array}{c}\mathrm{LT} \\
(\mathrm{mm})\end{array}$ & $0.000(-0.001,0.00)$ & 0.051 & $0.000(-0.001,0.00)$ & 0.606 & $0.000(-0.001,0.00)$ & 0.406 & 0.008 \\
\hline $\begin{array}{r}\mathrm{CR} \\
(\mathrm{mm})\end{array}$ & $0.007(0.006,0.007)$ & $<0.001$ & $0.004(0.003,0.005)$ & $<0.001$ & $0.002(0.001,0.003)$ & $<0.001$ & 0.109 \\
\hline $\begin{array}{l}\mathrm{AL} / \mathrm{CR} \\
\text { ratio } \\
\mathrm{BMI} \\
\left(\mathrm{kg} / \mathrm{m}^{2}\right)\end{array}$ & $0.000(0.000,0.001)$ & 0.267 & $0.000(0.000,0.000)$ & 0.984 & $0.000(0.000,0.000)$ & 0.161 & 0.041 \\
\hline $\begin{array}{l}\mathrm{SE} \\
\text { (D) }\end{array}$ & $0.035(0.010,0.060)$ & 0.006 & $0.023(-0.003,0.049)$ & 0.084 & $0.030(0.003,0.056)$ & 0.026 & 0.057 \\
\hline $\begin{array}{c}\mathrm{AL} \\
(\mathrm{mm})\end{array}$ & $0.033(0.021,0.046)$ & $<0.001$ & $0.010(-0.002,0.022)$ & 0.108 & $0.008(-0.005,0.021)$ & 0.214 & 0.076 \\
\hline $\begin{array}{l}\text { ACD } \\
(\mathrm{mm})\end{array}$ & $0.007(0.004,0.010)$ & $<0.001$ & $0.003(0.001,0.006)$ & 0.013 & $0.003(0.001,0.006)$ & 0.014 & 0.028 \\
\hline $\begin{array}{c}\mathrm{LT} \\
(\mathrm{mm})\end{array}$ & $-0.001(-0.003,0.001)$ & 0.222 & $0.000(-0.002,0.001)$ & 0.611 & $-0.001(-0.003,0.001)$ & 0.403 & 0.008 \\
\hline $\begin{array}{r}\mathrm{CR} \\
(\mathrm{mm})\end{array}$ & $0.011(0.009,0.014)$ & $<0.001$ & $0.005(0.002,0.007)$ & $<0.001$ & $0.005(0.002,0.008)$ & $<0.001$ & 0.078 \\
\hline $\begin{array}{l}\mathrm{AL} / \mathrm{CR} \\
\text { ratio }\end{array}$ & $0.000(-0.002,0.001)$ & 0.682 & $-0.001(-0.002,0.001)$ & 0.360 & $-0.001(-0.003,0.001)$ & 0.227 & 0.040 \\
\hline
\end{tabular}

Data in parentheses represent the 95\% confidence interval. All regression coefficients are derived from a separate regression model with the individual refraction or ocular biometric

components as the dependent variable, and height, weight, or BMI as the independent variable, adjusting for other covariates.

* Models for height are adjusted for weight, and vice versa. Models for BMI are not adjusted for either height or weight. PM, parental myopia; TO, time outdoors; NW, near work.

$+\mathrm{R}^{2}$ of final regression models. 
Page 15/15 